\title{
Preface to Special Issue on Climate Science for Service Partnership China
}

\author{
Stephen BELCHER ${ }^{1}$, Peter STOTT ${ }^{1}$, Lianchun $\mathrm{SONG}^{2}$, Qingchen $\mathrm{CHAO}^{2}$, Riyu $\mathrm{LU}^{3}$, and Tianjun $\mathrm{ZHOU}^{3}$ \\ ${ }^{1}$ Met Office, FitzRoy Road, Exeter, EX1 3PB, UK \\ ${ }^{2}$ National Climate Center, China Meteorological Administration, Beijing, 100081, China \\ ${ }^{3}$ Institute of Atmospheric Physics, Chinese Academy of Sciences, Beijing, 100029, China
}

Citation: Belcher, S., P. Stott, L. C. Song, Q. C Chao, R. Y. Lu, and T. J. Zhou, 2018: Preface to special issue on Climate Science for Service Partnership China. Adv. Atmos. Sci., 35(8), 897-898, https://doi.org/10.1007/s00376-018-8002-0.

This special issue of Advances in Atmospheric Sciences provides a selection of research highlights from the Climate Science for Service Partnership China (CSSP China). This pioneering partnership between China and UK based researchers has broken new ground in the development of climate science for services. By accelerating and enhancing collaborative science, CSSP China has built a strong foundation for services to support climate and weather resilient economic development and social welfare in China and the UK. In presenting some of the collaborative work undertaken in the project, this special issue illustrates the advantages of a sustained and ambitious scientific partnership developing leading edge research to support the climate services of the future. In this preface, we describe the genesis of the CSSP China project to develop science for services, explain the structure of the project, and consider some of the potential legacies.

Over the course of many years, researchers in China, UK and internationally have made significant advances in observing and understanding our planet's day-to-day weather and the longer-term climate, including understanding the drivers of changes, and methods and tools for predicting the future of weather and climate. With these scientific advances has come an increasing awareness of societal vulnerabilities to weather- and climate-related risks. These include loss of life from extremes of temperature, precipitation, wind and water levels.

CSSP China was launched in 2014 as a flagship project of the Newton Fund (channelled through the UK-China Research and Innovation Partnership in China). CSSP China was established to meet an emerging demand in both China and the UK to develop climate science to underpin an enhanced range of climate services. It builds on the core expertise of the China Meteorological Administration's National Climate Centre (CMA NCC) and the Institute of Atmospheric Physics (IAP) at the Chinese Academy of Sciences, the Met Office and other key UK and Chinese universities and institutes. Developing a successful and productive partnership has taken strong commitment from all parties to the common endeavour of developing climate science for services. Now, in its fifth year, the project has produced over 100 scientific papers and is supporting the development of enhanced climate services.

CSSP China is organised into five work packages, all of which are represented in this special issue:

(1) Monitoring, attribution and reanalysis. An example of research undertaken here is illustrated by the contribution by Williamson et al. (Page 899-904) who have shown how digitisation of old weather archives is allowing us to better understand how East Asian climate has changed over time.

(2) Global dynamics of climate variability and change. An example here is the paper by Bett et al. (Page 918-926), which is the result of a close collaboration between IAP, CMA and Met Office scientists. This work provides an excellent illustration of how a development in scientific understanding - in this case seasonal prediction — has enhanced a climate service, namely advice given about the likelihood of heavy rainfall in the Yangtze river region in summer 2016.

(3) East Asian climate variability and extremes, as represented by several papers including the paper by Zhao et al. (Page 927-941), which investigates the processes over the Tibetan Plateau that are so important for the water cycle over China.

(4) Development of models and climate projection systems. The paper by Zhang et al. (Page 1003-1020) provides a good example of how scientists from IAP, Nanjing University of Information Science and Technology, University of Reading, UK and Met Office have worked together to better understand the role of horizontal resolution in the representation of the global monsoon annual cycle in climate models.

(5) Joint development of prototype climate services. The paper by Hewitt and Golding (Page 905-908) provides a perspective on the development and pull-through of climate science to services in China.

A strong effort to coordinate across these work packages helps to ensure that the science developed in the project can be drawn together to improve climate services. These services, as the CSSP China project has demonstrated, have tremendous potential to be used by government, industry and society to help them make better-informed decisions and policies. From its inception, CSSP China has emphasised using science to co-develop climate services, and on ensuring that societal needs in China influence and guide the collaborative research programme. For example, UK-China collaborative work on the influence of El Nino on summer rainfall patterns in the Yangtze river basin has led to a breakthrough in seasonal forecasting for a region prone to severe floods and at risk of loss of lives and livelihoods. Seasonal forecasts produced collaboratively by 
China Meteorological Administration, supported by the Met Office, are routinely produced and used as part of a trial climate service to inform decisions about flooding and energy production. Feedback from decision makers informs on-going research, including supporting enhancements that users have requested to the service and requirements for further underpinning science research.

Another example of developing climate science for climate services concerns assessing the security of food supplies under a changing climate. CSSP China research has developed the understanding of the impacts of current and future climate variability and extremes on crops. These scientific advances are providing evidence to inform long-term planning in agricultural investments, which in turn can help ensure the stability of the food system in China, as well as in the UK and elsewhere in the world.

These examples illustrate how climate science can underpin enhanced climate services, and that the needs of the users of climate services inform the science being developed. In order to build strong individual and institutional partnerships CSSP China aims to build a legacy that can stand for many years to come. For example, the partnership has implemented a successful series of visiting scientist exchanges between the UK and China. It has also seen the development of a series of specialist workshops, for example bringing experts in attribution science together with early career researchers interested in assessing the role of climate change in extreme weather events in China.

Topic-specific workshops help build capacity in China for specialist areas of climate science such as attribution of extreme weather events. Likewise, the UK has benefitted from an enhanced appreciation of climate processes and variability in the East Asia region. Collectively climate modelling is advancing in both countries thanks to jointly addressing common modelling challenges. And a greater understanding has developed in both countries in how best to provide climate information to help individuals and organisations make climate smart decisions. Thus the essence of climate services, as set out by the World Meteorological Organisation in their Global Framework for Climate Services, has come closer to fruition. 